\title{
Fatty acid compositions in mucus and roe of haruan, Channa striatus, for wound healing
}

\begin{abstract}
1. Fatty acid profiles in the external mucus extract and roe of Channa striatus were determined using gas chromatography (GC).

2. The mucus samples were collected by inducing hypothermic stress $\left(\bar{I} 20^{\circ} \mathrm{C}\right.$ ) for about $1 \mathrm{hr}$, and the roe were collected from gravid females at night soon after they liberated their eggs in a spawning program.

3. All mucus and roe samples were freeze-dried, except a part of roe which was not.

4. The mucus extract contained unsaturated fatty acid (oleic acid, C18:1 and linoleic acid, C18:2) as a major component, $21.25 \%$ and $22.47 \%$ of total lipid.

5. For the freeze- and nonfreeze-dried roe, the major components of fatty acid were somewhat similar to the mucus but with higher percentages: $58.56 \%, 26.08 \%$ and $45.76 \%$, $20.94 \%$. Interestingly, the nonfreeze-dried roe contained a large proportion of arachidic acid, C20:0 (22.16\%), which was totally absent in the freeze-dried roe samples.

6. This profiling of the fatty acid mucus extract and roe is useful in strengthening the earlier claims that haruan possesses a potential remedy for wound healing (Mat Jais et al. 1994). Therefore, we are discussing the possibility of getting an optimum amount of the essential fatty acid for wound healing from various other parts of the fish without sacrificing the fish.
\end{abstract}

Keyword: Haruan; Channa striatus; Role in wound healing; Fatty acid profile; Arachidonic acid 